\title{
Segurança Alimentar: capacitação em boas práticas para colaboradores de escolas públicas de Petrolina-PE
} Food Safety: training in good practices for employees of public schools in Petrolina$P E$

\author{
SIMPLICIO, Keicy Layane Ribeiro. Tecnóloga/Tecnologia em Alimentos \\ IF Sertão-PE - Campus Petrolina. R. Maria Luzia de Araújo Gomes Cabral, 791 - João de Deus - Petrolina / PE - \\ Brasil. CEP: 56.316-686 / Telefone: (87) 98807.6978 / E-mail: keicylayane@hotmail.com
}

\section{SILVA, Ednaldo Gomes da. Doutor/Ciências Biológicas}

IF Sertão-PE - Campus Petrolina. R. Maria Luzia de Araújo Gomes Cabral, 791 - João de Deus - Petrolina / PE Brasil. CEP: 56.316-686 / Telefone: (87) 98851.7718 / E-mail: ednaldo.gomes@ifsertao-pe.edu.br

\section{RESUMO}

O termo segurança alimentar corresponde a garantia de acesso a alimentos com qualidade e segurança, de modo a não causar nenhum problema à saúde do consumidor. Para que se atinja esse fim, é indispensável a utilização de meios e mecanismos, tais como as boas práticas de fabricação e manipulação, análise de perigos e pontos críticos de controle, protocolos de procedimento operacional padrão e sistemas de qualidade 5S, entre outros. 0 ambiente escolar, por atender a uma grande demanda diária de merendas, se configura como meio onde o cuidado com o preparo das refeições requer atenção e treinamento constantes. Tendo em vista as considerações, este projeto visou capacitar merendeiras de escolas públicas estaduais da cidade de Petrolina-PE. Foram visitadas e capacitadas no total de onze escolas e vinte e quatro merendeiras, conforme o planejamento e cronograma da equipe técnica da secretaria de Educação.

Palavras-chave: Alimento seguro, capacitação para o trabalho, boas práticas.

\begin{abstract}
The term food security is the guarantee of access to food with quality and safety, so as not to cause any problem to consumer health. To achieve this end, the use of means and mechanisms such as good manufacturing and handling practices, hazard analysis and critical control points, standard operating procedure protocols and $5 \mathrm{~S}$ quality systems, among others, is indispensable. The school environment, because it attends to a great daily demand of snacks, is configured as a means where the care with the preparation of the meals requires constant attention and training. In view of the considerations, this project aimed to train picketers from state public schools in the city of Petrolina-PE. Eleven schools and twenty-four lunchrooms were visited and trained, according to the planning and schedule of the technical team of the Education Department.
\end{abstract}

Keywords: Safe food, job training, good practices. 
SIMPLICIO, K.L.R; SILVA, E.G

Segurança Alimentar: Capacitação em Boas Práticas para Colaboradores de Escolas Públicas de Petrolina-PE.

\section{Introdução}

A expressão 'segurança alimentar', de modo geral, corresponde à garantia de acesso a alimentos com qualidade e segurança, de modo que não causará nenhum problema à saúde do consumidor ao ingerir esse alimento, além de ter o acesso básico. Para ter controle de qualidade são imprescindíveis boas práticas e condições em relação ao ambiente onde aconteça a produção, entre outros pontos necessários. (FREITAS,2007)

Em estudos realizados por SENN (2017), foi estabelecida a definição de segurança alimentar, proposta em 1996 pela Cimeira Mundial da Alimentação: um conjunto de ações relacionadas à disponibilização de acesso a alimentos em quantidade e qualidade suficientes para satisfazer as necessidades humanas, e que sejam seguros e nutritivos, não causando assim malefícios à saúde.

A implementação da norma ISO 22000 tem como definição um sistema de gestão de segurança alimentar, onde são apontados perigos a segurança dos alimentos, procedimento de monitoramento, correções e ações corretivas que podem ser tomadas, caso haja limites críticos, entre outros. Tem como finalidade controlar os perigos e fornecer produtos seguros, abrangendo todas as partes que forem matéria de gênero alimentício, e tudo que os envolve, aplicando todas as medidas de segurança para garantir a segurança da produção dos alimentos. Assim, para aquelas empresas que tenham porte e responsabilidade, aplicam-se todos os requisitos da norma rigorosamente, permitindo receber a sua certificação. (AZEVEDO,2017)

Não obstante, existe a definição de capacitar, que é melhorar, habilitar, a qual desempenha em um profissional o aprimoramento de uma ou mais funções. A aquisição dessas competências é de suma importância para que o profissional seja uma referência em sua área. (TROMBETA,2016).

A capacitação para os manipuladores de alimentos e o controle de qualidade no preparo de alimentos são muito importantes, e envolvem as Boas Práticas de Manipulação, que por sua vez são técnicas e procedimentos adequados para o preparo de alimentos, que podem garantir qualidade e segurança higiênico-sanitária dos alimentos.

A segurança alimentar pode promover e aumentar o conhecimento técnico dos colaboradores, diminuindo os surtos de infeções alimentares. Todo esse sistema faz parte de um processo de aprendizado que auxilia o profissional a atingir a eficiência exigida no seu trabalho, incentivando o desenvolvimento de hábitos apropriados para o crescimento geral e a importância de se consumir um alimento seguro. A importância da capacitação é dar aos manipuladores conhecimentos teóricos necessários para capacitar e levar ao desenvolvimento e habilidades no trabalho com a área de alimentos (GÓES et al., 2001).

\section{Contaminação Alimentar}

A contaminação dos alimentos também pode ter início na produção da matéria-prima, estendendo-se às etapas de transporte, recepção, armazenamento. Durante a manipulação, pode haver contaminação por condições precárias de higiene de manipuladores, equipamentos, utensílios, 
SIMPLICIO, K.L.R; SILVA, E.G

Segurança Alimentar: Capacitação em Boas Práticas para Colaboradores de Escolas Públicas de Petrolina-PE.

ambiente e condições inadequadas de armazenamento dos produtos prontos para consumo. (ALMEIDA, 1998).

Por conta desses fatores, constata-se que as inspeções sanitárias sobre os estabelecimentos que produzem e manipulam alimentos são necessárias para garantir o consumo de produtos seguros e de qualidade. (SOUZA, 2006).

Face ao exposto, aplicam-se diversas ferramentas de qualidade, que visam à garantia da inocuidade na manipulação de alimentos, como: Boas Práticas de Fabricação (BPF), Procedimento Padrão de Higiene Operacional (PPHO), Análise de Perigos e Pontos Críticos de Controle (APPCC), Programa 5S, dentre outras.

Destarte, os programas de capacitação de manipuladores enfatizam a importância da saúde, incluem noções básicas de higiene pessoal e ambiental e destacam os danos que a ausência desses cuidados causa sobre a saúde do consumidor, conscientizando os manipuladores de seu papel na prevenção das Doenças Vinculadas por Alimentos - DVA's. Além de ressaltar a importância da conscientização dos consumidores sobre suas atitudes e, consequentemente, sobre os riscos de contaminação dos produtos em etapas posteriores às de produção e distribuição, para minimizar o aparecimento de DVA's e prevenir o desperdício de produtos (ZANDONADI et al., 2007).

\section{Material e métodos}

Os resultados deste trabalho foram obtidos mediante a execução de um projeto de extensão homônimo, ligado ao Programa Institucional de Bolsas de Extensão (PIBEX) do IF Sertão-PE. O projeto teve duração de onze meses, e foi desenvolvido de novembro de 2017 a outubro de 2018. Com anuência da GRE Petrolina, foram realizadas capacitações em boas práticas para as colaboradoras merendeiras nas Escolas Estaduais de Petrolina-PE, apresentadas no Quadro 1. As escolas possuíam em média de duas a três merendeiras. Inicialmente, foram realizadas reuniões, onde foram transmitidas todas as orientações sobre a realização do trabalho e o cronograma das visitas.

A capacitação dos manipuladores de alimentos foi realizada nas escolas, conforme as datas e horários indicado nas reuniões pela nutricionista ligada à GRE-Petrolina, responsável pelos estabelecimentos. Utilizou-se material didático elaborado no programa Microsoft Office Power Point, sendo apresentado em projetor multimídia. Como ferramenta de apoio, foram elaborados folders, cartazes e cartilhas informativas para os manipuladores, os quais serviram de complemento às explanações teóricas realizadas. 0 tempo médio das capacitações foi de aproximadamente $0,93 \mathrm{~h}$. Os temas foram divididos em 4 módulos: Módulo 01: Segurança dos Alimentos x Segurança Alimentar; Módulo 02: Boas Práticas e Procedimento Operacional Padronizado; Módulo 03: Análise de Perigo e Pontos Críticos de Controle; Módulo 04: Programa 5S. A capacitação foi elaborada de acordo com a RDC Anvisa 216/2004 e Portaria SES/RS n 1224/2014, onde se ressaltam atribuições considerando a necessidade constante de aperfeiçoamento das ações de controle sanitário na área de alimentos, visando à proteção da saúde da população.

Para verificar o nível de conhecimento inicial sobre Boas Práticas e os hábitos adotados pelos manipuladores de alimentos, a cada módulo apresentado foram realizadas perguntas orais especificas. 
A avaliação das condições higiênicas do local foi realizada na primeira visita a escola, onde houve o conhecimento do estabelecimento e dos manipuladores. A partir segunda visita foram aplicadas as capacitações. As escolas que participaram das visitas e capacitações constam no Quadro 1:

Quadro 1 - Localização das Escolas de rede pública que participaram das capacitações.

\begin{tabular}{|l|c|c|}
\hline \multirow{2}{*}{ Localização das Escolas (Petrolina-PE) } & \multicolumn{2}{|c|}{ Capacitaça (h) } \\
\cline { 2 - 3 } No Visitas & Tempo (h) \\
\hline Projeto N10 - Senador Nilo Coelho. & 2 & 1,00 \\
\hline Escola N11 - Projeto Senador Nilo Coelho. & 2 & 1,17 \\
\hline Vila Nova C-3, Projeto de Irrigação Nilo Coelho. & 2 & 0.92 \\
\hline Areia Branca. & 2 & 1,42 \\
\hline Cohab Massangano. & & 0,67 \\
\hline Projeto de Irrigação Nilo Coelho. & 2 & 0,67 \\
\hline Núcleo de Moradores 7 Projeto de Irrigação Nilo Coelho. & 2 & 0,67 \\
\hline Núcleo de Moradores 9 Projeto de Irrigação Nilo Coelho. & 1 & 0,67 \\
\hline Núcleo de Moradores 6 Projeto de Irrigação Nilo Coelho. & 2 & 0,92 \\
\hline Distrito de Cachoeira do Roberto. Afrânio - PE. & 1 & 1,00 \\
\hline Centro. Afrânio - PE. & 1 & 1,00 \\
\hline
\end{tabular}

Fonte: Autores (2019).

\section{Resultados e discussão}

\section{Primeiro momento: Visita as escolas que passaram pela triagem.}

No primeiro momento acorreram as visitas combinadas junto com o cronograma da nutricionista responsável pelas escolas. Nestas visitas foram observados pontos importantes, tais como a higienização do local, higiene alimentar, higiene das merendeiras, depósitos das merendas, armazenamento das frutas e carnes, uniformes das merendeiras, estoque de limpeza (produtos químicos), organização da geladeira e limpeza dos utensílios e registros de frequência de higienização da caixa d'água pelas terceirizadas (Gráfico 1). A partir desse momento de observação, foi necessário 
SIMPLICIO, K.L.R; SILVA, E.G

Segurança Alimentar: Capacitação em Boas Práticas para Colaboradores de Escolas Públicas de Petrolina-PE.

destacar as deficiências de recursos que ocorriam em cada escola, bem como as dificuldades que as merendeiras passavam diariamente. Isso permitiu uma construção mais orientada da proposta da capacitação, passando-se as sugestões de correção os pontos observados de uma forma que agregassem conhecimento, através de uma linguagem compatível com o nível de compreensão, e por fim transformar estas informações em hábitos adequados diários.

Gráfico 1 - Condições avaliadas nas visitas.

\section{- Não Conforme}

- Conforme
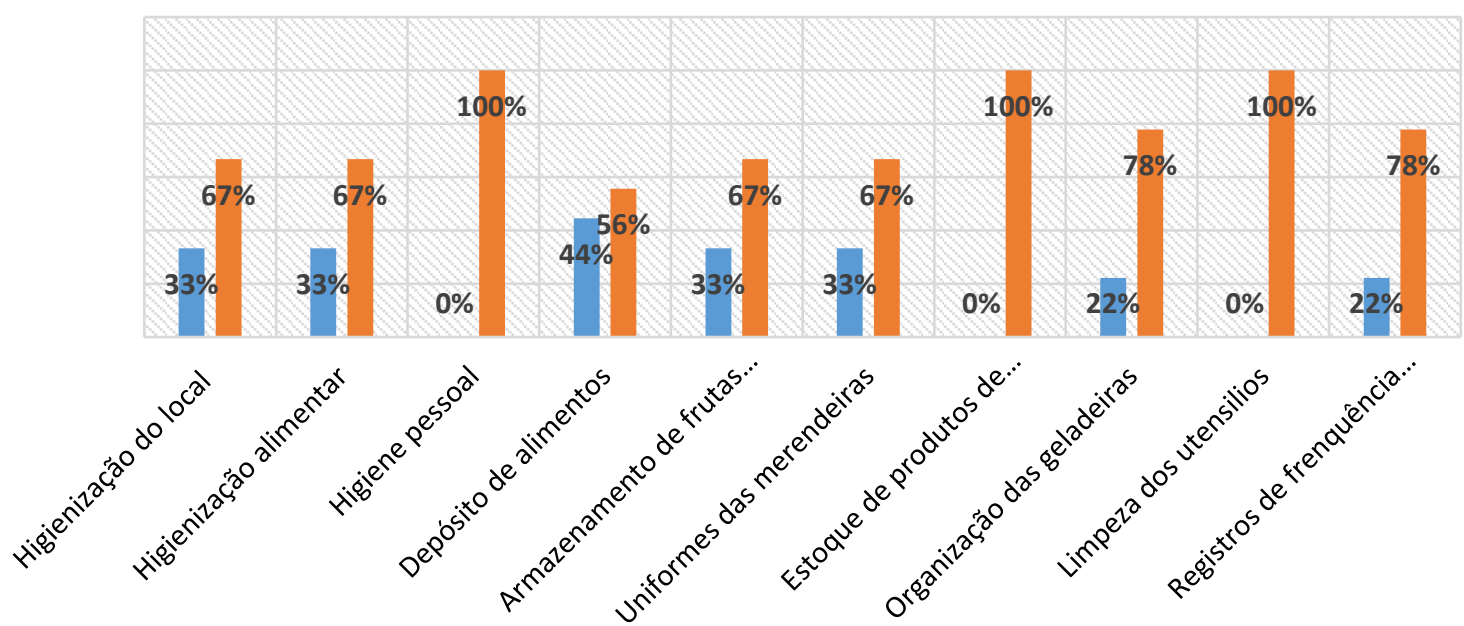

Fonte: Autores (2019).

Segundo momento: Visita e capacitação nas escolas.

Em um segundo momento de visita às escolas para capacitações, foi disponibilizado em cada unidade um espaço adequado para realizações das mesmas, ponto muito importante e ressaltado nas reuniões das programações ocorridas, para que não houvesse distração das merendeiras, de modo que estas pudessem focar-se, dialogar e tirar dúvidas, sem serem interrompidas por terceiros. De acordo com Leite et al. (2011), as capacitações contribuem para que as merendeiras possam realizar um auto avaliação quanto à execução dos procedimentos de higiene durante a rotina.

Foram confeccionados os materiais específicos com orientações e esclarecimentos sobre boas práticas na manipulação do alimento, visando esse preparo com condições seguras, e materiais didáticos ilustrativos, tais como: elaboração de slides para as aulas expositivas; cartilhas e folders para divulgação e acompanhamento dos conteúdos passados, como também para auxílio quando houver alguma dúvida no dia-a-dia.

Segundo Germano (2003), o uso de matérias didáticos para o acompanhamento do conteúdo favorece a atenção e compreensão nas capacitações.

Os conteúdos programados e apresentados em todas as capacitações realizadas foram os seguintes:

- Apresentação: Segurança Alimentar x Segurança dos Alimentos;

- Boas Práticas de Fabricação e Manipulação; 
SIMPLICIO, K.L.R; SILVA, E.G

Segurança Alimentar: Capacitação em Boas Práticas para Colaboradores de Escolas Públicas de Petrolina-PE.

- Procedimentos Operacionais Padronizados;

- Análise de Perigos e Pontos Críticos de Controle;

- Programa 5S.

Terceiro momento: Observações das visitas e capacitações aplicadas.

De acordo com as visitas realizadas com 24 merendeiras em 11 escolas envolvidas, tornou-se possível verificar que $69,23 \%$ das escolas se encontravam de acordo com as normas que regem os procedimentos de boas práticas para serviços de alimentação a fim de garantir as condições higiênicosanitárias do alimento preparado (Resolução RDC n. 216/2004).

Foi observada a falta de alguns requisitos a serem organizados, que não se encontravam ao alcance das merendeiras, como as condições de instalações sanitárias do local e a logística da distribuição de merendas. Em alguns momentos durante as visitas foram observadas entregas realizadas de forma inadequada, faltando higiene dos responsáveis, já que não havia uma avaliação crítica pela gestão da escola. Em situações como essas a responsabilidade é do gestor(a) escolar. Observou-se ainda que alguns produtos se encontravam próximos ao fim da data de validade e as lixeiras na mesma área de produção de alimentos.

De acordo com Silva e Cardoso (2011), por ser a primeira etapa que ocorre na unidade escolar, é imprescindível o monitoramento da recepção da matéria-prima, pois ele pode afetar o êxito no desenvolvimento das etapas subsequentes de processo do alimento. 0 transporte e o responsável pelas entregas realizadas na unidade escolar, como também das embalagens dos alimentos, devem ser rigorosamente monitorados, a fim de garantir que os produtos estão em boas condições e adequados à utilização.

Segundo Pistore e Gelinskib (2006), a adequação da área física e das condições de trabalho dos manipuladores constituem importante requisito para realização das boas práticas e, consequentemente, obter qualidade higiênico-sanitária dos alimentos servidos.

Obtivemos $28,57 \%$ das merendeiras com resultados como; o uso incompleto de uniforme; hábitos inadequados de higiene durante a produção, e em relação as escolas com avaliações no estoque; frutas armazenadas em locais inapropriados, como por exemplo; diretamente ao chão, próximo de produtos químicos, pão recebido e não armazenado em local adequado, limpo e higienizado, produtos em grande quantidade próximos ao vencimento da data de validade no estoque sem identificação para uso, logística de uso de produtos inobservante à FEFO (primeiro que vence é o primeiro que sai); e higiene do ambiente a desejar.

Um grande problema observado foi o manejo de resíduos, pois a quantidade do lixo acumulado era grande e os locais não dispunham de espaço físico adequado para o armazenamento deste lixo até o descarte, favorecendo a ocorrência de contato indireto. Em todas as escolas visitadas o lixo se encontrava acondicionado em área diretamente ligada à área de produção dos alimentos, podendo gerar contaminação cruzada. Bezerra (2014) ressaltou a importância dos recipientes coletores serem adequados, dimensionados e devidamente tampados em locais apropriados, sabendo que os restos de alimentos e lixo são focos de contaminação, e quando acumulados atraem insetos e pragas. 
SIMPLICIO, K.L.R; SILVA, E.G

Segurança Alimentar: Capacitação em Boas Práticas para Colaboradores de Escolas Públicas de Petrolina-PE.

Nas escolas em que foram verificadas essas situações, observou-se que havia uma resistência maior por parte das merendeiras, em situações como a realização das atividades incorretas, mesmo sabendo que não é permitido e quais consequências podem trazer, como o uso de adornos, calçados inadequados, formas de descarte do lixo de forma prática e sem cuidados, não separação em local inadequado do lixo, para que não ocorra atraso das refeições, entre outras situações. Diante dos comportamentos citados, não se sentiam bem em serem chamadas à atenção, possivelmente pela falta de hábito em adotarem as boas práticas. Essas situações justificam a necessidade de realização de capacitações periódicas, com condições estruturais e materiais, para que os manipuladores excutem em sua rotina laboral tudo que for transmitido nesses treinamentos (SILVA; CARDOSO, 2011).

Durante as capacitações foram observadas em alguns participantes a falta de atenção e indisposição durante o desenvolvimento das ações. Isso pode explicar o motivo da resistência e das não conformidades encontradas. Pela falta de conhecimento das merendeiras, houve uma propensão à repetição de suas atividades mesmo de forma inadequada. Não obstante, outro fator com dificuldade foi a escolaridade dos participantes, mesmo tendo sido verificado e considerado durante o planejamento e desenvolvimento dos conteúdos aplicados. Cerca de 38,10\% das merendeiras não tinham conhecimento adequado e precisaram de ajuda para entender mais a parte teórica dos conteúdos. Entre outros fatores, a resistência à mudança, de forma geral e também nas organizações, sejam elas grandes ou pequenas, é um dos elementos que precisam de mais atenção, tendo como objetivo a aquisição de novos valores que integrem a cultura de uma empresa (FANTINATO: GARCIA, 2017).

Como resultado, $23,81 \%$ das participantes apresentaram pouco ou nenhum conhecimento quanto a alguns itens avaliados nos conteúdos das capacitações abordadas, principalmente quando foram realizadas perguntas durante a capacitação. Afirmaram não ter recebido cursos sobre o conteúdo. Felizmente houve, por parte da maioria, bastante interesse e participação, o que contribuiu significativamente para resultados positivos ao longo das capacitações.

As demais $76,19 \%$ das merendeiras presentes tiveram excelente desempenho, e manifestaram interesse para que houvessem mais capacitações, pois disseram compreender a importância dos conteúdos para a rotina.

Em torno de 50\% das merendeiras ressaltaram certos limites em suas funções, pela falta de recursos imposto a merenda das escolas, e também reclamaram da falta de pagamento, o que acarreta um certo desgaste em suas atividades, bem como contribuindo para a não conformidade no processo. Ao verificar essas informações, observou-se que pela falta de materiais e ferramentas adequadas, como utensílios para manipulação de alimentos, ocorreu a dificuldade na realização das atividades. Além disso, a frequente troca de empresas terceirizadas, responsáveis pela contratação das merendeiras, impactou o desenvolvimento das atividades realizadas em todas as cadeias produtivas alimentares das escolas participantes.

Foi percebida também a falta de tratamento adequado dispensado às merendeiras, pois mesmo com a existência de avisos para que houvesse o acesso à cozinha apenas por pessoas autorizadas e devidamente trajadas, gestores, professores e demais integrantes da comunidade escolar não obedeceram, dificultando assim o trabalho das merendeiras. Nos estudos de Bezerra 
SIMPLICIO, K.L.R; SILVA, E.G

Segurança Alimentar: Capacitação em Boas Práticas para Colaboradores de Escolas Públicas de Petrolina-PE.

(2014), foram relatadas situações semelhantes, como a falta de controle de acesso de pessoas ao serviço de alimentação, bem como o layout e dimensionamento das edificações, que podem comprometer a produção adequada dos alimentos, por conta da área de produção imprópria ao fluxo de processos.

Adicionalmente, torna-se fundamental a compreensão por parte dos gestores, diretores e de toda a comunidade escolar da importância de todas as questões relacionadas à alimentação no âmbito da escola. Entre as dificuldades na implementação de algumas práticas e mudanças no trabalho dos manipuladores, constata-se a falta de valorização, apoio e, ainda, conhecimento das orientações por parte de alguns desses atores na escola (SCARPARO et al., 2014). Assim, no contexto da alimentação escolar, o papel dos diretores das escolas, os quais estão diretamente e diariamente em contato com os manipuladores, é o de ser aliados no processo educacional, supervisionando a prática e retomando aspectos relacionados à formação.

Portanto, é imperativo que os profissionais tenham conhecimento dos assuntos abordados nas formações de manipuladores, seja participando das mesmas ou por meio de informações enviadas às escolas pelas nutricionistas responsáveis e presentes nas visitas.

Embora o levantamento das condições higiênico-sanitárias tenha utilizado uma amostragem pequena frente ao número de escolas públicas existentes em Petrolina, estudos similares indicam a existência de problemas comuns na maioria das escolas. De acordo com estudos realizados, em média em 40\% das escolas as informações sobre a educação higiênico-sanitária dos manipuladores não são aplicadas de forma correta, Entrementes, ocorre ainda a deficiência no monitoramento contínuo de informações e realização de capacitações sistemáticas (SILVA; CARDOSO, 2011).

Pelos resultados obtidos durante as capacitações, em $60 \%$ das escolas visitadas podem-se considerar que os atributos de qualidade na manipulação e preparo de alimentos foram observados e praticados de forma correta.

Acreditamos que, com o final das capacitações, as participantes poderão tanto agregar como construir saberes para exercer novos conhecimentos, agregando melhorias em suas atividades. A prática de atividades realizadas com consciência também será útil para a preservação do meio ambiente, por conta dos resíduos gerados.

É importante ressaltar que as oportunidades criadas pelas capacitações foram necessárias para as merendeiras envolvidas, para poderem perceber e compreender a importância de como os conhecimentos adquiridos vão fazer parte da rotina profissional. Por desempenharem um papel de grande importância para a sanidade dos produtos, principalmente para os alimentos sujeitos a uma intensa manipulação durante o seu preparo e distribuição, há a necessidade de que os manipuladores participarem de capacitações periódicas, para reforçar bons hábitos profissionais e exercerem plenamente suas funções.

De acordo com os Regulamentos Técnicos utilizados no desenvolvimento das capacitações obtivemos com as comparações dos mesmos os seguintes resultados (Gráfico 2): 
SIMPLICIO, K.L.R; SILVA, E.G

Segurança Alimentar: Capacitação em Boas Práticas para Colaboradores de Escolas Públicas de Petrolina-PE.

Gráfico 2 - Desempenho das merendeiras relacionado ao conteúdo ministrado e desenvolvimento das atividades diárias em comparação com os regulamentos técnicos.

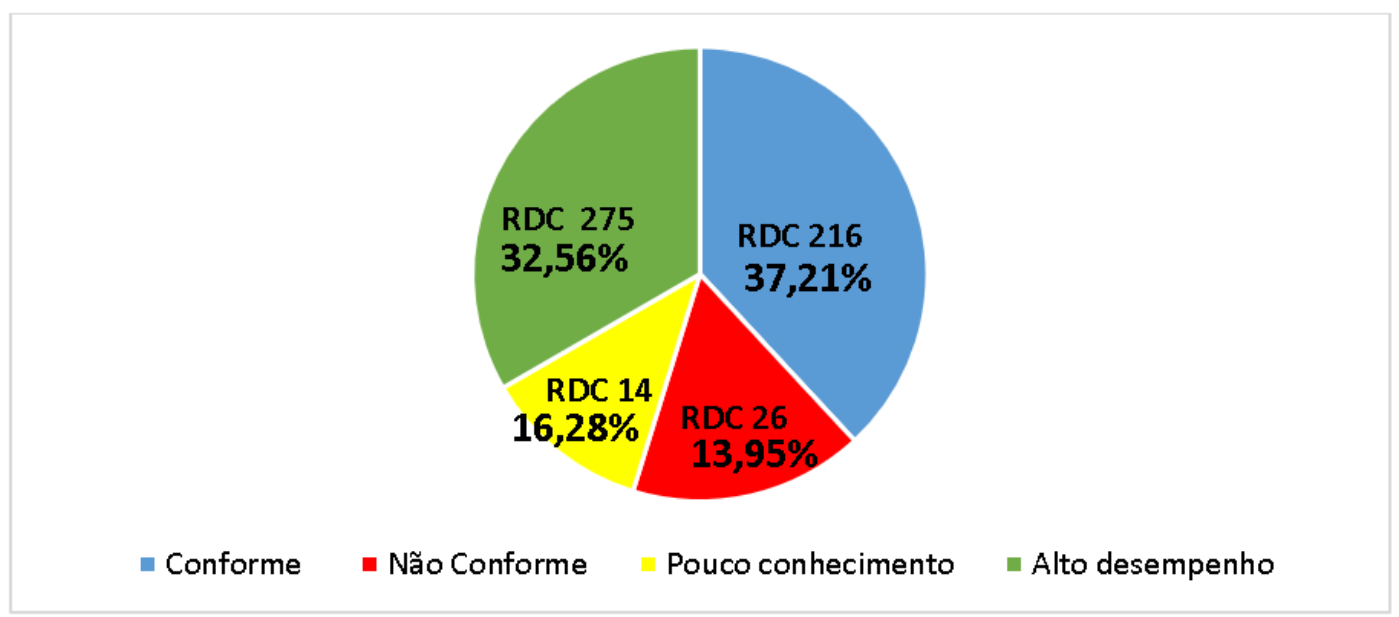

Fonte: Autores (2019).

Em comparação com as RDC 216, obtivemos conformidades de 38\%. Nos resultados são estabelecidos procedimentos de Boas Práticas para a realização das atividades diárias das merendeiras, que eram aplicadas nos respectivos serviços, como: alimentos preparados ao consumo, fracionamento, armazenamento, antissepsia, boas práticas para garantir a qualidade higiênicosanitária e a conformidade dos alimentos, registros conforme de controle integrado de vetores e pragas urbanas para incorporação das ações preditivas e corretivas destinadas a impedir fatores que comprometam a qualidade higiênico-sanitária do alimento, desinfecção e higienização do ambiente e utensílios com frequência adequada, resíduos oriundos da área de preparação e das demais áreas descartadas corretamente (Resolução RDC nº. 216, 2004).

As não conformidades observadas (14\%), referem-se as atividades inadequadas desenvolvidas pelas merendeiras, bem como os seus conhecimentos em relação a RDC 26. Ela rege o emprego da alimentação saudável e adequada, compreendendo o uso de alimentos variados, seguros, entre outros fatores. 0 direito à alimentação escolar, visando garantir a segurança alimentar e nutricional. 0 conhecimento para garantir a aquisição, o transporte, a estocagem e o preparo/manuseio de alimentos coma adequadas condições higiênico-sanitárias até o consumo pelos alunos atendidos pelo programa (Resolução RDC nº. 26, 2013).

Com $17 \%$ nas atividades avaliadas e conteúdos ministrados, podemos observar o pouco conhecimento das merendeiras sobre a presença de matérias estranhas causadas por manipulação e hábitos inadequados nas atividades realizadas, tendo como consequência as Doenças Veiculadas por Alimentos (DVA's). Em comparação com a RDC 14, observou-se que não compreendiam a questão da presença de matérias estranhas macroscópicas e microscópicas que podem causar riscos à saúde humana e/ou as indicativas de falhas na aplicação das boas práticas na cadeia produtiva de alimentos e bebidas (Resolução RDC $n^{\circ}$ 14, 2014).

0 alto desempenho das merendeiras referiu-se à RDC 275, onde são estabelecidas as ferramentas necessárias para a garantia das condições higiênico-sanitária no momento de preparo e 
SIMPLICIO, K.L.R; SILVA, E.G

Segurança Alimentar: Capacitação em Boas Práticas para Colaboradores de Escolas Públicas de Petrolina-PE.

manipulação dos alimentos. Mostraram conhecimento 33\%, tanto nas atividades realizadas diariamente em que foram avaliadas, como nos conteúdos ministrados e a importância da aplicação das Boas Práticas entre outros ferramentais fundamentais para o controle higiênico-sanitário.

\section{Conclusões}

Após a realização dessas ações, conclui-se que:

- A importância dada aos cuidados com a manipulação dos alimentos, por parte de alguns colaboradores das escolas visitadas, ainda é baixa;

- A falta de treinamento específico para os colaboradores de algumas das escolas visitadas é um dos fatores identificados como mais impactantes para prevenção de riscos na manipulação alimentar;

- Para que tenha sua eficiência efetivada, a capacitação dos colaboradores deve ser feita de forma sistemática e contínua, de modo a fortalecer a cultura das boas práticas na segurança alimentar.

- Considerando a relevância desse trabalho para a garantia da produção de alimentos seguros, princípios de higiene pessoal e de alimentos, deve ser indispensável e continuamente reforçado e monitorado por um profissional da área, para que sejam realizadas atividades de educação, no formato de formação inicial e continuada ou equivalente.

\section{Referências}

ALMEIDA C. R. O sistema HACCP como instrumento para garantir a inocuidade dos alimentos. Higiene Alimentar. v. 12, n. 53, p. 12-20, 1998.

ANVISA. Cartilha sobre boas práticas para serviços de alimentação.

Disponível em: http://portal.anvisa.gov.br/documents /33916/389979/

Cartilha+Boas+Pr\%C3\%A1ticas+para+Servi\%C3\%A7os+de+Alimenta\%C3\%A7\%C3\%A3o/d8671f20-2dfc4071-b516-d59598701af0>. Acesso em 20.04.2018.

AZEVEDO, R.T. Sistemas de gestão da segurança alimentar - introdução à norma ISO 22000. Disponível em: http://naturlink.pt/ar ticle.aspx?menuid=7\&cid=93961\&bl=1\&viewall=true>. Acesso em 20.04.2018.

BECKER, B. Segurança alimentar. Disponívelem:<https://bdebecker.files.wordpress.com/2015/03/4trabalho-modelo-formatado.pdf $>$.Acesso em 20.04.2018.

BRASIL. Ministério da Educação - PNAE. Resolução - RDC Nº 26, de 17 de Junho de 2013. Dispõe sobre o atendimento da alimentação escolar aos alunos da educação básica. Brasília, DF, 17 de Junho de 2013. 
SIMPLICIO, K.L.R; SILVA, E.G

Segurança Alimentar: Capacitação em Boas Práticas para Colaboradores de Escolas Públicas de Petrolina-PE.

BRASIL. Agência Nacional de Vigilância Sanitária- ANVISA. Resolução - RDC № 14, de 28 de Março de 2014. Estabelecer as disposições gerais para avaliar a presença de matérias estranhas macroscópicas e microscópicas, indicativas de riscos à saúde humana e/ou as indicativas de falhas na aplicação das boas práticas na cadeia produtiva de alimentos e bebidas, e fixar seus limites de tolerância. Brasília, DF, 28 de Março de 2014.

BRASIL. Agência Nacional de Vigilância - ANVISA. Resolução - RDC № 275, de 21 de Outubro de 2002. Estabelecer Procedimentos Operacionais Padronizados que contribuam para a garantia das condições higiênico-sanitárias necessárias ao processamento/industrialização de alimentos, complementando as Boas Práticas de Fabricação. Brasília, DF, 21 de Outubro de 2002.

BRASIL. Agencia Nacional de Vigilância Sanitária- ANVISA. Resolução - RDC № 216, de 15 de Setembro de 2004. Estabelece procedimentos de boas práticas para serviço de alimentação, garantindo as condições higiênico-sanitárias do alimento preparado. Diário Oficial da União, Brasília, DF, 17 setembro de 2004.

BRASIL, Ministério do Trabalho. Secretaria de Segurança e Saúde no Trabalho. Portaria n²4, de 29 de dezembro de 1994. Programa de controle Médico de Saúde Ocupacional (NR-7). Disponível em: http://redsang.ial.sp.gov.br/site/docs_leis/st/st13.pdf.

FLENGER, Marilene.; TEXEIRA, E. B. A implementação das boas práticas de fabricação de fabricação num restaurante de ljuí/RS: uma estratégia para geração de conhecimento. Disponível em: <http://www.abepro.org.br/biblioteca/ENEGEP2004_Enegep0703_0474.pdf>. Acesso em 20.04.2018.

FANTINATO, S.R.C.; GARCIA, P.D. Estudo da resistência à mudança e sua interferência na implantação de um sistema de gestão da qualidade. Revista Espacios, v.38, n.34, p.30-43. Disponível em: http:/ /www.revistaespacios.com/a17v38n34/a17v38n34p30.pdf. Acesso em 24.07.2018.

FREITAS, M.C.S.; PENA, P.G.L. Segurança alimentar e nutricional: a produção de conhecimento com ênfase nos aspectos da cultura.

GERMANO, P. M. L. et al. Manipuladores de Alimentos: Capacita? É preciso. Regulamentar? Será preciso? Higiene Alimentar, São Paulo. 2000.

GERMANO M.I.S. Promoção da saúde: desafio para os profissionais envolvidos no treinamento de manipuladores de alimentos [tese]. São Paulo: Universidade de São Paulo; 2002.

GERMANO, P.M.L.; GERMANO, M.I.S. Higiene e Vigilância Sanitária de Alimentos. 2.ed. ver. ampl. São Paulo: Varela, 2003. 
SIMPLICIO, K.L.R; SILVA, E.G

Segurança Alimentar: Capacitação em Boas Práticas para Colaboradores de Escolas Públicas de Petrolina-PE.

GÓES, J. A. et al. Capacitação dos manipuladores de alimentos e a qualidade da alimentação servida. Higiene Alimenta, São Paulo. 2001.

LEITE, Catarina Lima; CARDOSO, Ryzia de Cassia Vieira; GÓES, José Ângelo Wenceslau; FIGUEIREDO, Karla Vila Nova de Araújo; SILVA, Edleuza Oliveira; BEZERRIL, Mariângela Melo; VIDAL JÚNIOR, Permínio Oliveira; SANTANA, Aisi Anne Carvalho. Formação para merendeiras: uma proposta metodológica aplicada em escolas estaduais atendidas pelo programa nacional de alimentação escolar, em Salvador, Bahia. Rev. Nutr., Campinas, 24(2):275-285, mar./abr., 2011.

MACHADO, L.A. Segurança alimentar e nutricional e soberania alimentar. Disponível em: <http://www4.planalto.gov.br/consea/acesso-a-informacao/institucional/conceitos>. Acesso em 20.04.2018.

MENEZES, F. Panorama atual da segurança alimentar no Brasil. Disponível em: <http://amarbresil.pagesperso-orange.fr/documents/ secual/san.html>. Acesso em 20.04.2018.

Ministério da Saúde. Agência Nacional de Vigilância Sanitária. (2004) Resolução-RDC nº. 216, de 15 de setembro de 2004. Brasília.

NASCIMENTO, F. das C. A. do. Aspectos Sócio - Econômicos das Doenças Veiculadas pelos Alimentos. Nutrição em Pauta, São Paulo, 2000.

NASSIF, L.N. FDA admite: carne de frango contém cancerígeno. Disponível em: <http://advivo.com.br/comentario/re-fda-admite-carne-de-frango-contem-cancerigeno-13>. Acesso em 20.04.2018.

PANZA, S. G. A.; BROTHERHOOD, R.; ANDREOTTI, A.; REZENDE, C.; BALERONI, F. H.;PAROSCHI, V. H. B. Avaliação das Condições Higiênico-Sanitárias Durante a Manipulação dos Alimentos,em um Restaurante Universitário, Antes e Depois do Treinamento dos Manipuladores. São Paulo: ANATEC, 2006.

PISTORE, A.R.; GELINSKIB, J.M.L.N. Avaliação dos conhecimentos higiênico-sanitários dos manipuladores de merenda escolar: fundamento para treinamento contínuo e adequado. Revista Higiene Alimentar, São Paulo, v.20, n. 146, p.17-20. Nov-2006.

NATALI, M. Praticando o 5S: na indústria, comércio e vida pessoal. São Paulo: Editora STS, 1995. 101p.

PRAXEDES, P. C. G. Aspectos da qualidade higiênico sanitária de alimentos consumidos e comercializados na cidade de São Remo. 2003. 120 f. Dissertação (Mestrado em Epidemiologia Experimental e Aplicada ao Controle das Zoonoses) - Universidade de São Paulo, São Paulo, 2003. 
SIMPLICIO, K.L.R; SILVA, E.G

Segurança Alimentar: Capacitação em Boas Práticas para Colaboradores de Escolas Públicas de Petrolina-PE.

SENN. D. Introdução à segurança alimentar. Disponível em:

http://archive.sswm.info/print/8235?tid=3225. Acesso em 21.04.2018.

Secretária da Saúde. Órgão de Vigilância Sanitária Estadual e Municipal. (2014) Portaria Nº 1224/2014.

SCARPARO ALS, BALDASSO PL, LOPES EFS, VENZKE JG, ROCKETT FC.Material orientativo para formação de manipuladores de alimentos que atuam na alimentação escolar. Centro Colaborador em Alimentação e Nutrição do Escolar da Universidade Federal do Rio Grande do Sul (CECANE UFRGS). Fundo Nacional de Desenvolvimento da Educação (FNDE). Brasília (DF): Ministério da Educação, 2014.

SILVA, Valteneide Bitencourt; CARDOSO, Ryzia de Cássia Vieira. Controle da qualidade higiênicosanitária na recepção e no armazenamento de alimentos: um estudo em escolas públicas municipais de Salvador, Bahia. 2011. Disponível em: https://periodicos.sbu.unicamp.br/ojs/index.php/san/article/view/8634687/2606. Acesso em 21.07.2018.

SOUZA, L. H. L. A manipulação inadequada dos alimentos: fator de contaminação. Higiene Alimentar, v. 20, n.146, p. 32-39, 2006.

TROMBETA, A. Os desafios da manutenção para 2016.Disponível em: <https://pt.linkedin.com/pulse/os-desafios-da-manuten\%C3\%A7\%C3\%A3o-para-2016-me-alessandrotrombeta-mba>. Acesso em 20.04.2018. 